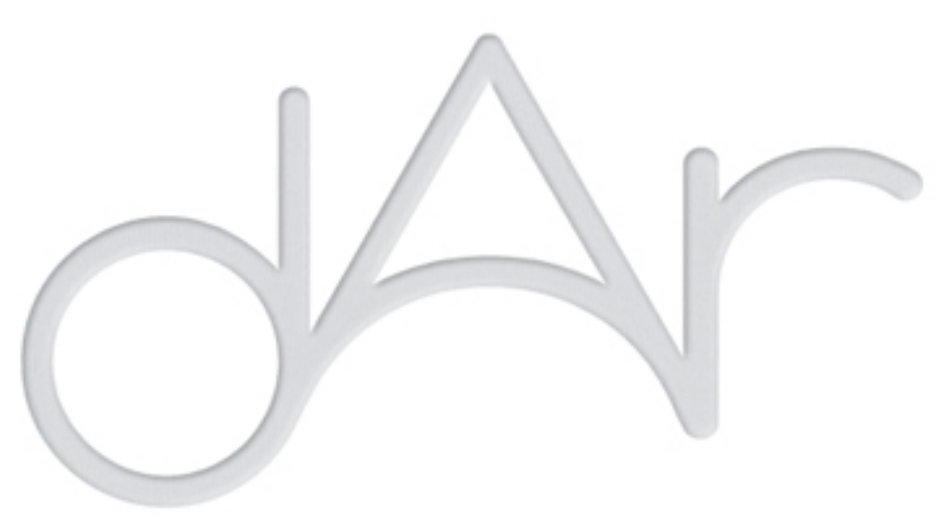

Fichas de Inventário: SICG (Sistema Integrado de Conhecimento e Gestão do IPHAN Estudo de Caso em Patrimônio Rural

\author{
Autor(es): $\quad$ Martins, Sandra Cristina Fernandes; Rossignolo, João Adriano \\ Publicado por: CEAUCP \\ URL \\ persistente: URI:http://hdl.handle.net/10316.2/9125 \\ DOI: $\quad$ DOI: http://dx.doi.org/10.14195/2182-844X_1_7 \\ Accessed : $\quad$ 26-Apr-2023 03:41:14
}

A navegação consulta e descarregamento dos títulos inseridos nas Bibliotecas Digitais UC Digitalis, UC Pombalina e UC Impactum, pressupõem a aceitação plena e sem reservas dos Termos e Condições de Uso destas Bibliotecas Digitais, disponíveis em https://digitalis.uc.pt/pt-pt/termos.

Conforme exposto nos referidos Termos e Condições de Uso, o descarregamento de títulos de acesso restrito requer uma licença válida de autorização devendo o utilizador aceder ao(s) documento(s) a partir de um endereço de IP da instituição detentora da supramencionada licença.

Ao utilizador é apenas permitido o descarregamento para uso pessoal, pelo que o emprego do(s) título(s) descarregado(s) para outro fim, designadamente comercial, carece de autorização do respetivo autor ou editor da obra.

Na medida em que todas as obras da UC Digitalis se encontram protegidas pelo Código do Direito de Autor e Direitos Conexos e demais legislação aplicável, toda a cópia, parcial ou total, deste documento, nos casos em que é legalmente admitida, deverá conter ou fazer-se acompanhar por este aviso.

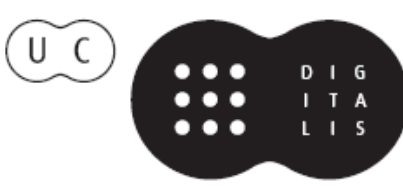


$6^{\circ}$ Seminário de Arquitectura em Terra em Portugal ( $6^{\circ}$ ATP) $9^{\circ}$ Seminário Ibero-americano de Construção e Arquitectura com Terra (9 SIACOT)

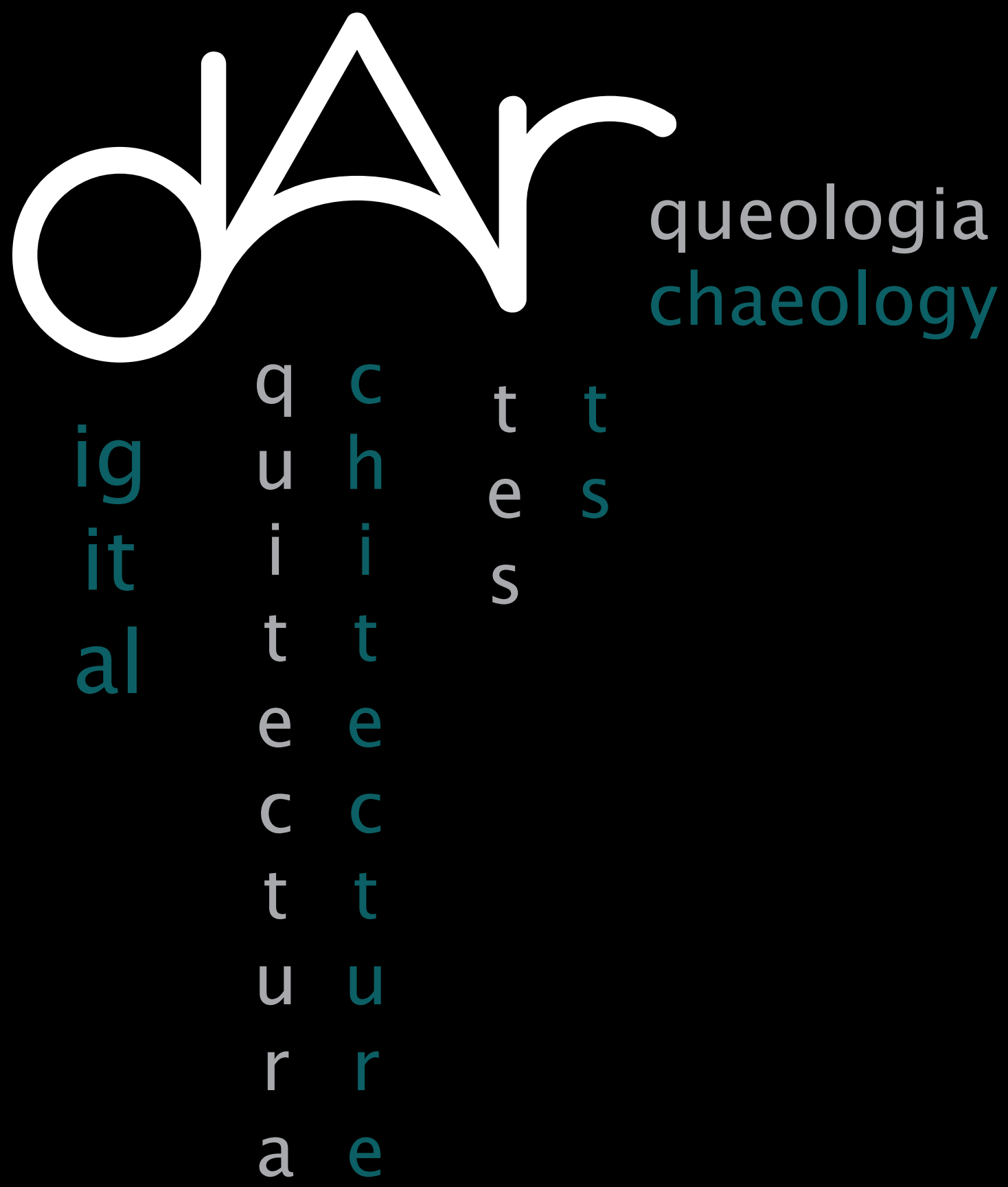




\title{
FICHAS DE INVENTÁRIO: SICG (SISTEMA INTEGRADO DE CONHECIMENTO E GESTÃO) DO IPHAN - ESTUDO DE CASO EM PATRIMÔNIO RURAL
}

\author{
Sandra Cristina Fernandes Martins* (Brazil) \\ Centro Universitário Nossa Senhora do Patrocínio, CEUNSP
}

João Adriano Rossignolo** (Brazil)

Escola Engenharia São Carlos EESC - USP

\begin{abstract}
RESUMO
O patrimônio rural da cidade de Campinas tem em sua configuração técnicas construtivas em que se utiliza a terra. A partir da segunda metade do século XIX impulsionada pela expansão da economia cafeeira e pela riqueza acumulada pelo açúcar, a cidade tornou-se detentora de uma vasta área com fazendas rurais, inseridas na atual malha urbana. Podemos explanar que a conservação da arquitetura e das construções em terra, foi um dos temas discutidos no I Fórum Nacional do Patrimônio Cultural de 2009, realizado em Ouro Preto, Minas Gerais. As construções em terra estão presentes na maioria das edificações rurais e para se conceituar o patrimônio cultural rural é preciso reconhecer e valorizar todos os elementos naturais e constituídos quanto às técnicas, às crenças, os costumes e o saber fazer do meio rural. Muitos modelos de gestão para preservação do patrimônio estão em uso, mas o modelo SICG do IPHAN apresenta novidades. O objetivo deste artigo é apresentar o modelo de gestão SICG (Sistema Integrado de Conhecimento e Gestão) do IPHAN (Instituto do Patrimônio Histórico e Artístico Nacional) do Brasil com seus modelos de fichas de inventário de patrimônios históricos e através da análise de uma ficha de inventário contribuir para o questionamento de métodos de proteção e conservação. Saber reconhecer o valor patrimonial das técnicas construtivas da arquitetura rural da terra roxa (região de Campinas) na qual predominam as taipas e outras técnicas nos fará delimitar um justo lugar no valor de memória do patrimônio. A metodologia tem como base o estudo da arquitetura rural, além da análise das fichas de inventário do SICG (1). A documentação pesquisada inclui textos, fichas, mapas, assim como material gráfico e iconográfico. Tomamos como objeto de análise o estudo de caso da fazenda de café Mato Dentro em Campinas que possui casa-sede, capela e tulha tombadas pelo Condephaat e pelo Condepacc órgãos estaduais e municipais respectivamente de proteção do patrimônio cultural. Com grande relevância para a cidade devido seu contexto na história campineira. Tem várias técnicas construtivas tais como a taipade-pilão, o pau-a-pique, a alvenaria de tijolos, a alvenaria de pedra, o ladrilho hidráulico e a telha de colo ou capa-canal. Sendo assim, questionamentos se formaram devido à inovação do assunto e a idéia de utilização de uma tecnologia eficaz.
\end{abstract}

Palavras-chave: Fichas de inventário, IPHAN-SICG, Arquitetura rural brasileira.

*sancfm@terra.com.br

**j.a.rossignolo@gmail.com 


\section{INTRODUÇÃO}

Em 2009, durante o I Fórum Nacional do Patrimônio Cultural, em Ouro Preto, no estado de Minas Gerais, realizado pelo IPHAN discutiu-se sobre os desafios, as estratégias e experiências de uma nova gestão para o patrimônio cultural brasileiro.

Dentre vários assuntos abordados foi discutido e distribuído a publicação do manual do Sistema Integrado de Conhecimento e Gestão (SICG) que é uma ferramenta de apoio para a gestão e proteção do patrimônio cultural desenvolvido para reunir um amplo e diversificado conjunto de informações referentes às cidades históricas brasileiras.

Esse instrumento tem o objetivo de integrar dados sobre o patrimônio cultural, com foco nos bens de natureza material, reunindo em uma base única informações sobre cidades históricas, bens móveis e integrados, edificações, paisagens, arqueologia, patrimônio ferroviário, conjuntos rurais e outras ocorrências do patrimônio cultural no Brasil.

O SICG é constituído por um conjunto de fichas agrupadas em três módulos: Conhecimento, Gestão e Cadastro. Cada Módulo corresponde a uma esfera de abordagem do patrimônio cultural e possui fichas estruturadas para a captura e organização de informações conforme o objetivo do estudo ou inventário. Os módulos foram idealizados para permitir uma abordagem ampla do patrimônio cultural, partindo do geral para o especifico, com recortes temáticos e territoriais, e possibilitando a utilização de outras metodologias, como o Inventário Nacional de Referencias Culturais-INRC (2).

Nestes termos, é relevante comentar que as fichas de inventário são propostas como ferramentas de auxílio na gestão e planejamento do patrimônio cultural, além de propor um modelo e metodologia única de documentação e inventário de bens culturais. Vale a pena ressaltar que existe uma ficha específica para os conjuntos rurais objeto de análise desta pesquisa.
O presente artigo trata de apresentar $O$ modelo de gestão SICG do IPHAN do Brasil e através da análise da ficha (M304 conjuntos rurais) ao objeto de estudo Fazenda Mato Dentro de Campinas, no estado de São Paulo, contribuir para o questionamento de métodos de proteção e conservação.

\section{A HISTÓRIA DO PATRIMÔNIO RURAL NO BRASIL}

O estudo do patrimônio arquitetônico rural vem despertando o interesse de engenheiros e arquitetos por seu potencial de alavancar e viabilizar empreendimentos no espaço não-urbano. Também historiadores, geógrafos, economistas, turismólogos, arquitetos e empresários tradicionalmente ligados ao mundo rural começam a descobrir nesse conjunto uma oportunidade de agregar valor a suas propriedades ou a seus negócios, atraindo o homem da cidade carente das raízes rurais (Argollo Ferrão, 2007, p.92).

O termo patrimônio rural foi citado pela primeira vez na recomendação de Paris instituída pela Conferencia Geral da Unesco em 1962. Esse documento dispõe sobre a salvaguarda das paisagens e sítios naturais ou rurais. No artigo II, item 5, destaca-se que "a preservação é quando possível, a restituição do aspecto das paisagens e sítios, naturais e urbanos, devido à natureza ou à obra do homem, que apresentem um interesse cultural ou estético, ou que constituam meios naturais característicos" (IPHAN, 1995, p.99).

É considerado patrimônio rural:

Os antigos casarões e senzalas, colônias e casas de trabalhadores dispersas construídas com técnicas tradicionais da arquitetura rural ou com materiais e técnicas alternativas de construção, toda arquitetura vernacular, antigas capelas rurais, engenhos e casas de máquinas, o próprio maquinário desativado, antigos equipamentos de produção e energia (monjolo, rodas d’água, etc.), elementos e sistemas estruturais antigos (pontes, diques, barragens, etc.), o espaço físico destinados às manifestações culturais 
locais (praças, terreiros, largos, vilarejos, etc.) (Argollo Ferrão, 2007, p.94).

Panis e Oliveira (2008) relatam que além de todos esses elementos destacados por Argollo Ferrão, acrescentam-se as manifestações artístico-culturais, as formas de expressão, as comidas, as vestimentas, os utensílios domésticos e de trabalho, entre outros.

Argollo (2004) narra que os estudos sobre arquitetura rural no Brasil tem evoluído nos últimos anos de acordo com a lógica das intensas mudanças porque passa o ambiente rural no Pais. Normalmente, ao se enfocar a arquitetura rural, remete-se logo à idéia de uma paisagem singela, composta por pequenos sítios ou enormes glebas sem a necessária infraestrutura física capaz de dotar o território de elementos que otimizem a produção agropecuária e ao mesmo tempo a qualidade de vida dos trabalhadores e empresários rurais. A paisagem rural brasileira, com seu imenso patrimônio cultural, confere aos estudos sobre a arquitetura rural uma dimensão socioeconômica importante.

Assim, como forma de minimizar os impactos de nos custos de um edifício se faz necessário levantar dados, estudar seu programa de necessidades, verificar quem são seus usuários, seu projeto arquitetônico, sua relação com o entorno, fluxos, circulação, e principalmente o valor que Ihes é atribuído por transmitir para gerações futuras. Mas quando pensamos em edifícios históricos tombados, a importância é ainda maior na medida em que permite a antecipação de problemas e possíveis incompatibilidades comuns no projeto de restauro. Para além do custo financeiro, há um ganho para a sociedade com a garantia da preservação de sua memória construída (Brum, 2008, p.238).

O desgaste natural sofrido pelo tempo faz com que esses edifícios históricos entrem em um processo de degradação, além de outras ações como vandalismo, descuido, polvição e calamidades naturais como ventos, chuvas, inundações entre outros. A preservação do patrimônio arquitetônico não é uma tarefa fácil.

O inventário caracteriza-se como "uma operação permanente, dinâmica e sistemática, visando o cadastro de manifestações humanas, em suas diferentes criações espontâneas e formas, e de potencialidades naturais" (IPAC, 2001, p.2) (3).

Cabe ainda ressaltar que a Declaração de Amsterdã nos relata sobre a importância da difusão de inventários como base para a conservação.

Seria desejável que esses inventários fossem largamente difundidos, notadamente entre as autoridades regionais e locais, assim como entre os responsáveis pelo planejamento físicoterritorial e pelo plano urbano como um todo, a fim de chamar sua atenção para as construções e zonas dignas de serem protegidas. Tal inventário fornecerá uma base realista para a conservação, no que diz respeito ao elemento qualitativo fundamental para a gestão dos espaços (IPHAN, 1995, p. 234).

\section{FAZENDA MATO DENTRO}

A propriedade rural conhecida como Fazenda Mato Dentro surgiu no início do século XIX e inseriu-se exemplarmente no padrão de ocupação fundiária e de produção agrícola dominantes na região campineira. Formada em 1806, a partir da gleba de terra desdobrada pelo TenenteCoronel Joaquim Aranha Barreto de Camargo essa propriedade inicia-se como engenho e plantação de açúcar tornandose em poucos anos produtora de café (Vaderrama et al, 2008).

Atualmente a área da fazenda encontra-se dentro do tecido urbano hoje transformada num parque ecológico de uso público. A fazenda Mato Dentro possui características do final do século XVIII. Segundo, PUPO (1983):

"... uma das características das velhas construções do final do século XVIII e primeiros anos do século XIX está nos telhados de quatro águas sobre um quadrilátero perfeito de construção, 
ou de três águas com partes térreas adidas e sobrado; (...), e mais casas térreas como a de Joaquim Aranha no engenho-fazenda Mato Dentro (...), homem viajado, conhecedor do fausto de outras regiões (...). A sua residência rural também teve requintes, como sua porta principal com entalhes, seu forro de salão nobre, e com a singularidade de ser a casa um perfeito quadrilátero, telhado de quatro águas, dispondo de um outro lanço, à direita da casa, com piso inferior (e comunicação interior), no alinhamento da fachada principal, destinada ao cômodo de serviços, cozinha, dispensa, etc. Assim, o quadrilátero principal (47 x 17 m) dispõese de uma planta de rígida simetria desenvolvida em torno de um grande salão central (a varanda) e de um longo corredor e se destinou, exclusivamente, aos cômodos sociais e íntimos.

Foram encontrados técnicas e materiais de construção como a taipa-de-pilão, o pau-a-pique, a alvenaria de tijolos e alvenaria de pedra. O ladrilho hidráulico e a telha de colo ou capa-canal também eram desenvolvidos na fazenda. A técnica construtiva de taipa-de-pilão é de importância para caracterizar esta época de transição entre a arquitetura do açúcar e a do café. (SILVA, 2006).

\section{ESCALAS DE ATUAÇAO NA DEFESA DO PATRIMÔNIO NO BRASIL}

Precisamos tornar claro que no Brasil, devido sua extensa área, existem órgãos em três escalas de gestão que cuidam da defesa do patrimônio cultural brasileiro. Como o enfoque é o estado de São Paulo e a cidade de Campinas temos como exemplos: Na escala federal o IPHAN (Instituto de Defesa do Patrimônio Artístico Nacional, Condephaat (Conselho de Defesa do Patrimônio Artístico, Arqueológico, Artístico e Turístico do Estado de São Paulo) na escala estadual e Condepacc (Conselho de Defesa do Patrimônio Cultural de Campinas) na escala municipal. Esses três órgãos praticam tombamento e preservação e estão ligados ao governo.

\section{SICG - SISTEMA INTEGRADO DE CONHECIMENTO E GESTÃO}

SICG é uma ferramenta de apoio desenvolvida pelo departamento de Patrimônio material e fiscalização do IPHAN para a gestão e proteção do patrimônio cultural desenvolvido para reunir um amplo e diversificado conjunto de informações referentes às cidades históricas brasileiras.

Esse instrumento tem o objetivo de integrar dados sobre o patrimônio cultural, com foco nos bens de natureza material, reunindo em uma base única informações sobre cidades históricas, bens móveis e integrados, edificações, paisagens, arqueologia, patrimônio ferroviário, conjuntos rurais e outras ocorrências do patrimônio cultural no Brasil.

É constituído por um conjunto de fichas agrupadas em três módulos: Conhecimento, Gestão e Cadastro. Cada Módulo corresponde a uma esfera de abordagem do patrimônio cultural e possui fichas estruturadas para a captura e organização de informações conforme o objetivo do estudo ou inventário. Os módulos foram idealizados para permitir uma abordagem ampla do patrimônio cultural, partindo do geral para o específico, com recortes temáticos e territoriais, e possibilitando a utilização de outras metodologias, como o Inventário Nacional de Referências Culturais - INRC (voltado para a identificação de bens de natureza imaterial). (SICG, 2009, p.9).

Como um instrumento em construção, nem todos os modelos de fichas estão concluídos, e muito menos foram dadas explicações durante o fórum de como será o funcionamento do seu cadastro, o SICG tem como uma das aplicações fundamentais o desenvolvimento de inventários de Conhecimento. Esses inventários de conhecimento têm como objetivo formar uma base de informações aplicadas à construção de uma rede de Proteção do Patrimônio em todos os estados e municípios do Brasil (SICG, 2009, p.11). No fluxograma abaixo (Fig. 1) se pode ter uma compreensão geral do que é composto este sistema. 

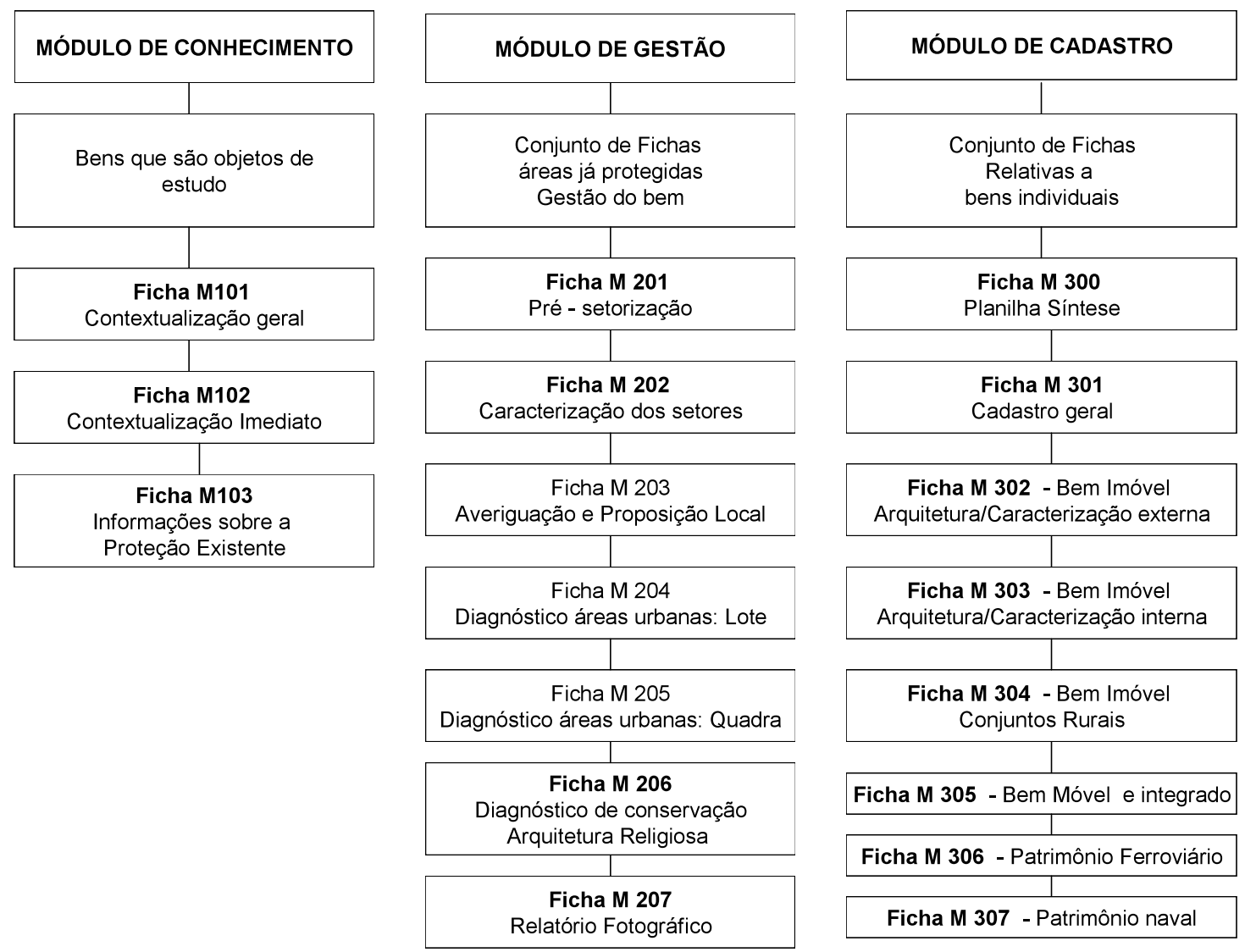

Fig. 1. Fluxograma dos módulos do SICG. Fonte: autores, 2009.

O módulo de Conhecimento visa reunir informações que contextualizem a história e no território, os bens que são objetos de estudo. Organiza, portanto, as informações provenientes de universos culturais temáticos ou territoriais. $\mathrm{O}$ de gestão reúne um conjunto de fichas cujo enfoque são as área já protegidas e tem obrigação de fazer a gestão. E finalizando temos o módulo de cadastro que reúne bens de interesse ou já protegidos possui uma ficha padrão comum e aprofundando os conhecimentos fichas especializadas sobre arquitetura, bens móveis e integrados, conjuntos rurais, patrimônio ferroviário, etc. (SICG, 2009, p.10).

O sistema será informatizado e atuará estando estruturado em base word e excel, seus usuários serão o IPHAN, estados, municípios e entidades parceiras como universidades, centros de estudos, museus e outros. Futuramente poderá ser acessada para consulta via internet facilitando a pesquisa. Ainda não está disponível para acesso. Entretanto não podemos deixar de comentar que no Brasil já existe vários modelos de fichas de inventário entre os diversos órgãos que atuam na proteção e conservação do patrimônio cultural como: CONDEPHAAT (Conselho de defesa do Patrimônio Histórico, Artístico, Arqueológico e Turístico do Estado de São Paulo); CSPC (Conselho Setorial do Patrimônio Cultural de Campinas; DPH (Departamento de patrimônio Histórico) - São Paulo; Inepac (Instituto Estadual do Patrimônio Cultural do Rio de Janeiro); IPAC (Instituto do Patrimônio Artístico e Cultural da Bahia); SPHAN/Pró Memória - Ouro Preto. Voltando ao SICG relatamos que para áreas rurais, foco da pesquisa, existe um modelo de ficha M304 - Bem imóvel - Conjuntos rurais preenchido com os dados da Fazenda Mato Dentro (ver Tabela 1).

\section{CONSIDERAÇÕES FINAIS}

O SICG é um conceito inovador no quadro 


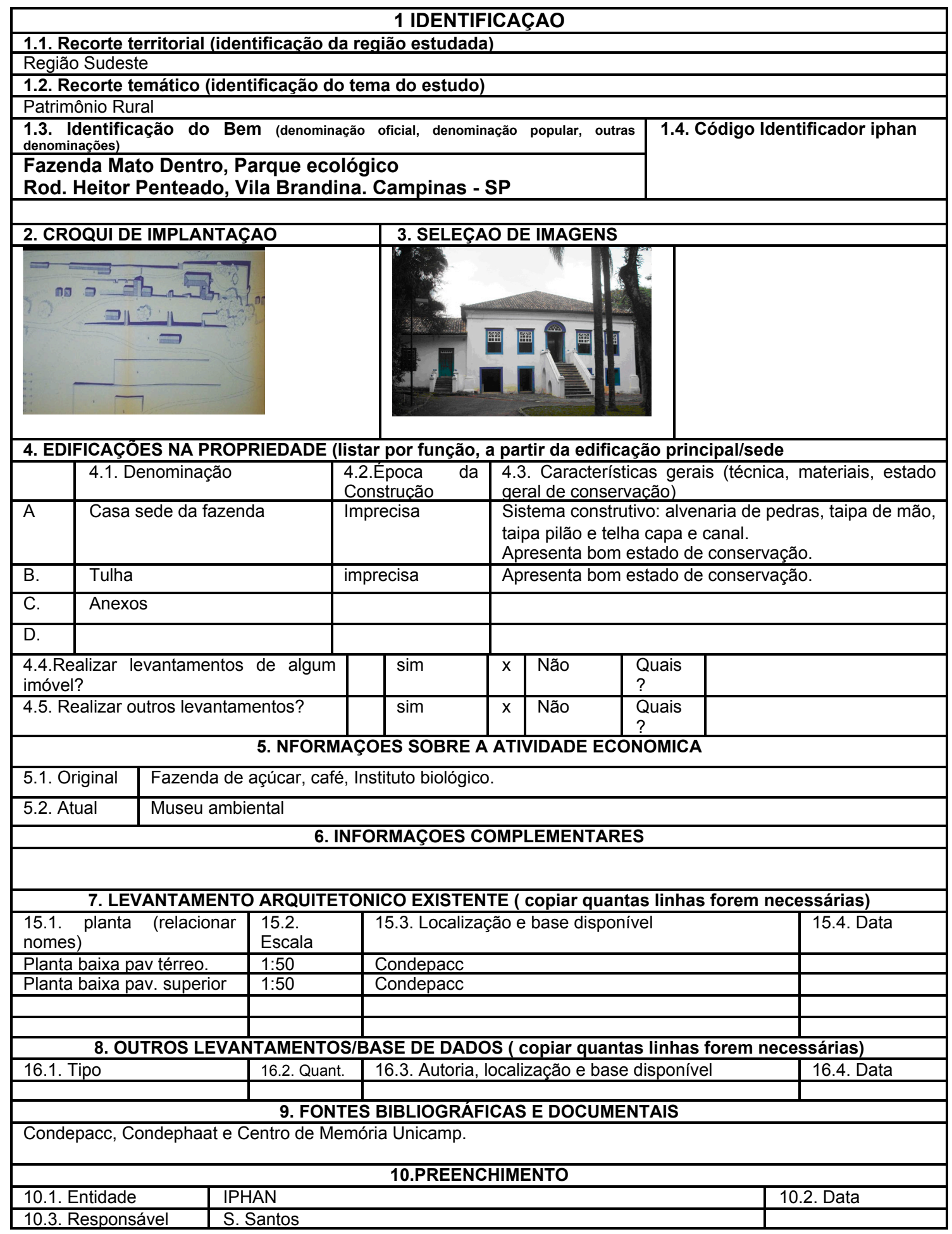

Tabela 1. Módulo de Cadastro Ficha M304. Créditos: IPHAN, 2009.

de preservação do patrimônio brasileiro.

Percebe-se que existe uma preocupação e um esforço coletivo dos diversos órgãos que atuam na preservação do patrimônio para que o sistema se concretize e que possa direcionar as pesquisas em uma base de dados única. Contudo, o sistema ainda não está em operação e pouca literatura e outras informações se têm sobre o assunto. 
O que sentimos é que existem limitações evidentes nas questões dos módulos. Um programa de tal grandeza poderia ter pensado na inclusão de outros módulos depois do módulo de cadastro como, por exemplo, módulo de conservação e módulo de manutenção do bem. Isso iria gerar outras fichas (ou itens) avaliando o estado de conservação (fichas de caracterização das construções) e fichas de manutenção onde poderíamos acompanhar o processo e o desempenho das estruturas dentre outros.

Uma das funções das fichas de inventário é catalogar; sendo assim utilizadas como instrumentos de ponta do processo, poderiam contemplar as patologias comuns através de campos mais específicos onde seriam descritos os métodos de intervenção nas edificações históricas reunidas através das mãos dos fiscais de obra. Muitas inovações na área da tecnologia poderiam agilizar o processo de diagnóstico e tratamento dessas patologias como, por exemplo, a utilização de ensaios não destrutivos como o ultrassom. Essa tecnologia eficaz e de custo acessível poderia minimizar a morosidade do processo de prevenção e conservação.

Acreditamos que toda intervenção em edificações históricas deve ser precedida de investigação técnico-científica. Entendese por investigação técnico-científica a utilização das técnicas mais avançadas de caracterização física e química dos materiais, auxiliando a identificação dos agentes e mecanismo de deterioração. Isso iria desvendar o estado de degradação do bem rural e auxiliar no processo de prevenção e manutenção das construções em terra. O modelo de ficha M304 não contribui para gerar um histórico específico sobre as manutenções e os possíveis restauros.

Com o início operacional do sistema SICG muitos dos modelos propostos para as fichas de inventário poderão sofrer mudanças passíveis devido ao uso. Sendo assim, outros questionamentos e sugestões poderiam ser relatados aqui, mas uma das vantagens do sistema será futuramente a agilidade na integração de dados sobre o patrimônio cultural.

E para concluir, a motivação para a realização deste artigo surge do interesse geral na reabilitação das construções rurais com ênfase na utilização da área de tecnologia para que a preservação e gestão dos patrimônios seja contributo fundamental para a memória coletiva da população.

\section{Bibliografía}

Argollo Ferrao, A. M. (2007). Arquitetura rural e o espaço não urbano. Revista Labor\&Engenho, n० 1. Campinas, 89-100.

Argollo Ferrao, A. M. (2004). Arquitetura Rural dentro do Contexto sobre Patrimônio e Paisagens Culturais. (Relatório de Pós Doutorado, Barcelona [EST]: ETSAB-UPC, 2004).

Brum, C. V. C. et al. (2009). Impacto do projeto de climatização na reabilitação de edificações históricas. Simpósio Brasileira de Qualidade do projeto no Ambiente Construído. IX Workshop Brasileiro de Gestão do Processo de Projeto na Construção de edifícios, São Carlos. 18 a 20 de Novembro 2009.

Instituto do Patrimônio Histórico e Artístico Nacional. (1995). Cartas Patrimoniais. Brasília: IPHAN/Ministério da Cultura. Cadernos de Documentos, $n^{\circ} 3$, p. 343.

Instituto do Patrimônio Artístico e Cultural da Bahia - IPAC (2009). Acesso em jul. 2009, 15:45 em http://www.ipac.ba.gov.br/site/conteudo/ institucional/apresentacao/\#content.

Panis, M. e Oliveira, M. R. S. (2009). Paisagem e arquitetura rural: O caso da Região Pelotense/ RS. Revista Labor \& Engenho: Planejamento, patrimônio e paisagem, vol. 1 ( $\left.n^{\circ} 2\right), 2-16$. Campinas. Acesso em 04/07/2009 em http:// www.labore.fec.unicamp.br.

Prefeitura Municipal de Campinas. CONDEPACC. Emenda nº04 de 27 de novembro de 1990.

Pupo, C. M. M. (1983). Campinas, Município no Império: fundação e constituição, usos familiares, a morada, sesmarias, engenhos e fazendas. São Paulo: Imprensa Oficial do Estado.

Silva, Á. P. (2006). Engenhos e fazendas de café em Campinas (Séc. XVIII - Séc. XX), São Paulo. Anais do Museu Paulista, vol. 14, jun. 2009. São Paulo: Universidade de São Paulo, 81-119. 
SICG - Sistema Integrado de Conhecimento e Gestão. Realização, (2009). Brasilia: Publicação do IPHAN - Departamento de Patrimônio Material e Fiscalização.

Valderrama, B. B.; Oliveira, M. R. S. e Martins, S. (2008). Arquitetura rural da terra roxa: o caso das fazendas Pau d'Alho e Mato Dentro do município de Campinas no estado de São Paulo. Anais do II Congresso de Arquitetura e Construção com terra no Brasil e VII Seminário Ibero-Americano de Construção com Terra, São Luís, 2008.

Notas

(1) SICG: Sistema Integrado de Conhecimento e Gestão do departamento de Patrimônio Material e Fiscalização.

(2) INCR - Inventário Nacional de Referências Culturais é uma metodologia de pesquisa desenvolvida pelo IPHAN que tem como objetivo produzir conhecimento sobre os domínios da vida social aos quais são atribuídos sentidos e valores e que, portanto, constituem marcos e referências de identidade para determinado grupo social.

(3) IPAC - Instituto do Patrimônio Artístico e Cultural da Bahia

In: http://www.ipac.ba.gov.br/site/conteudo/ institucional/apresentacao/\#content 